\title{
Brief communication: Understanding solar geoengineering's potential to limit sea level rise requires attention from cryosphere experts
}

\author{
Peter J. Irvine $^{1}$, David W. Keith ${ }^{1}$, and John Moore ${ }^{2,3}$ \\ ${ }^{1}$ Harvard John A. Paulson School of Engineering and Applied Sciences, Cambridge, MA 02138, USA \\ ${ }^{2}$ Joint Center for Global Change Studies, College of Global Change and Earth System Science, \\ Beijing Normal University, Beijing, 100875, China \\ ${ }^{3}$ Arctic Centre, University of Lapland, Rovaniemi 96101, Finland
}

Correspondence: Peter J. Irvine (peter_irvine@ fas.harvard.edu)

Received: 11 December 2017 - Discussion started: 26 January 2018

Revised: 9 July 2018 - Accepted: 11 July 2018 - Published: 27 July 2018

\begin{abstract}
Stratospheric aerosol geoengineering, a form of solar geoengineering, is a proposal to add a reflective layer of aerosol to the stratosphere to reduce net radiative forcing and so to reduce the risks of climate change. The efficacy of solar geoengineering at reducing changes to the cryosphere is uncertain; solar geoengineering could reduce temperatures and so slow melt, but its ability to reverse ice sheet collapse once initiated may be limited. Here we review the literature on solar geoengineering and the cryosphere and identify the key uncertainties that research could address. Solar geoengineering may be more effective at reducing surface melt than a reduction in greenhouse forcing that produces the same global-average temperature response. Studies of natural analogues and model simulations support this conclusion. However, changes below the surfaces of the ocean and ice sheets may strongly limit the potential of solar geoengineering to reduce the retreat of marine glaciers. High-quality process model studies may illuminate these issues. Solar geoengineering is a contentious emerging issue in climate policy and it is critical that the potential, limits, and risks of these proposals are made clear for policy makers.
\end{abstract}

\section{Future sea level rise and the potential of solar geoengineering}

How far sea levels would rise under some scenario of future climate change depends mainly on global temperature rise, and uncertainties in projections rise rapidly as warming increases more than $2{ }^{\circ} \mathrm{C}$ above preindustrial conditions (Jevrejeva et al., 2016; Kopp et al., 2014). Most of this uncertainty is due to a lack of agreement on how the large ice sheets will respond (Bamber and Aspinall, 2013; Oppenheimer et al., 2016). For example, two recent high-profile publications made conflicting estimates of Antarctica's contribution to sea level rise by 2100 with a best guess of $10 \mathrm{~cm}$ (Ritz et al., 2015) and around $1 \mathrm{~m}$ (DeConto and Pollard, 2016).

A rapid transition towards a carbon-free economy will reduce additional temperature increases but the temperature response to cumulative emissions - and thus the impact on sea level - will remain for millennia without measures beyond emissions cuts (Clark et al., 2016). Two broad categories of measures might reduce long-term commitments to global sea level rise: solar geoengineering and atmospheric carbon removal. Solar geoengineering, which describes a set of proposals to increase Earth's albedo, is not a substitute for emissions cuts. But it could offer an independent means to temporarily reduce radiative forcing and thus the impacts of climate change, and so be a complement to emissions cuts. The two responses may be synergistic: carbon removal can reduce the long-term driver of climate change, while solar geoengineering might temporarily reduce the net radiative forcing. Our focus is on assessing solar geoengineering impact on sea level rise because existing research is quite limited and because its effects (per unit of temperature change) may not be the same as those achieved by reducing temperature by de-carbonizing. 
The human, environmental, and financial costs of sea level rise are substantial. The rapidly rising concentration of population and infrastructure in coastal cities means that costs of flooding without adaptation measures are projected to be USD 50 trillion per year by 2100 , while coastal protection would cost USD 15-70 billion per year (Hinkel et al., 2014). One important consideration is that sea level rise is not globally uniform, due to a combination of local factors: glacial isostatic adjustment and ground water extraction resulting in local vertical land movement, the self-gravitational influence of mass loss from the large ice sheets, and changes in ocean dynamics and rates of volume expansion of warming sea water. Taking all these together, Jevrejeva et al. (2016) find that $80 \%-90 \%$ of global coastlines will experience sea level rises about twice as large as the global ocean average.

Whilst some, including one of the authors (Keith), have been working on solar geoengineering for decades, more than 10 times as many articles have been published on the topic since 2007 than before. Whilst many proposals for solar geoengineering have been made, work now focuses on a few of the more likely candidates. Marine cloud brightening, a proposal to increase the albedo of marine stratocumulus by releasing sea salt aerosols from ships (Latham, 1990); cirrus cloud thinning, a proposal to suppress cirrus cloud persistence, and hence reduce their warming effect, by releasing ice nuclei to encourage the formation of larger, shorter-lived ice crystals (Mitchell and Finnegan, 2009); and stratospheric aerosol geoengineering, a proposal to release aerosol particles into the stratosphere to create a persistent reflective aerosol layer scattering a small fraction of incoming light back to space (Budyko, 1977). Of these proposals, stratospheric aerosol geoengineering is the most likely to be technically achievable. Releasing a few teragrams of material per year into the lower tropical stratosphere $(\sim 20 \mathrm{~km})$ would produce an aerosol layer with global coverage. Multiple, independent feasibility assessments of the proposal conclude that this could be achieved at a cost of the order of USD 1 billion per teragram using high-altitude jets (McClellan et al., 2012; Moriyama et al., 2016; Robock et al., 2009). The clouds and aerosols chapter of the last IPCC report concluded that "there is medium confidence that stratospheric aerosol [geoengineering] is scalable to counter the [radiative forcing] from increasing [greenhouse gases (GHGs)] at least up to approximately $4 \mathrm{~W} \mathrm{~m}^{-2}$ [approximately the forcing of a doubling of $\mathrm{CO}_{2}$ concentrations]" (Boucher et al., 2013). For this reason, here we focus on stratospheric aerosol injection and unless otherwise stated, solar geoengineering will hereafter refer to stratospheric aerosol geoengineering only.

The tens of climate model studies of solar geoengineering prior to 2013 were summarized in the last IPCC report (Boucher et al., 2013): "models consistently suggest that [solar geoengineering] would generally reduce climate differences compared to a world with elevated GHG concentrations and no [solar geoengineering]; however, there would also be residual regional differences in climate (e.g., tem- perature and rainfall) when compared to a climate without elevated GHGs". This reduction in the magnitude of many climate trends means that solar geoengineering may offer a means to reduce the risks of climate change (Keith and Irvine, 2016).

Beyond its effect on climate (which will be discussed in more depth below), stratospheric aerosol injection would have a number of side effects (Irvine et al., 2016). Simulations of stratospheric sulfate aerosol injection (the most commonly analyzed scenario of stratospheric aerosol geoengineering) consistently show that it would lower ozone concentrations, delaying the recovery of the ozone hole by a number of decades (Pitari et al., 2014; Tilmes et al., 2012). As well as scattering light back to space, the stratospheric aerosol cloud would also scatter light downwards, shifting the balance of direct to diffuse light, which could boost plant productivity but would reduce the efficiency of concentrating solar power plants (Kravitz et al., 2012). The aerosols would also absorb radiation, warming the stratosphere and affecting stratospheric chemistry and dynamics (Tilmes et al., 2009). The magnitude of these side effects will depend on the properties of the injected aerosols, and alternatives to sulfate particles may have substantially reduced side effects (Keith et al., 2016).

In its seminal 2009 report (Shepherd et al., 2009), the United Kingdom's Royal Society predicted that the social and political challenges posed by solar geoengineering would be far greater than the technical ones. Its potentially low cost could mean that individual nations or very wealthy individuals could have the resources to deploy solar geoengineering (Weitzman, 2014). The global impacts of any largescale deployment could be the source of international tension and poses a serious challenge for international governance (Victor, 2008).

Technical analyses and climate model simulations suggest solar geoengineering may offer a means to reduce the risks of climate change but it would also introduce new risks, both physical and sociopolitical. A robust understanding of the potential and limits of solar geoengineering as a means to reduce climate risks is a necessary, but not sufficient, basis for a much broader discussion of this idea. This study aims to highlight the key questions around the sea level rise response to solar geoengineering that only the sea level and cryosphere community will be able to resolve. In Sect. 2, we provide a brief review of studies into the sea level rise response to solar geoengineering, noting the methodological shortcomings and gaps in the literature. In Sect. 3, we evaluate how the effects of solar geoengineering and a reduction in GHG forcing on sea level rise could differ, discussing its potential effects on thermosteric sea level rise, surface mass balance, and on ocean-driven melt of ice shelves and discharge from marine glaciers. In Sect. 3.2 we make an initial assessment on the relative efficacy of solar geoengineering as seen in the Geoengineering Model Intercomparison Project (GeoMIP). 
In Sect. 4, we summarize the results briefly and make a number of recommendations for research.

\section{Critical review of existing literature on solar geoengineering and sea level rise}

As solar geoengineering would reduce temperatures across the world, offsetting some of the warming from elevated GHG concentrations, it is clear that to first order it would reduce both the thermal expansion of the oceans and the melting of land ice. Wigley (2006), Moore et al. (2010), and Irvine et al. (2012) illustrate this using simple models of the sea level rise response to a range of solar geoengineering scenarios. Moore et al. (2010) used a semiempirical model relating radiative forcing to sea level calibrated by tide gauge data from the past 200 years to evaluate a range of different forms of solar geoengineering. Wigley (2006) and Irvine et al. (2012) adapted the simple models used in the Intergovernmental Panel on Climate Change Third and Fourth Assessment Reports, respectively, to evaluate a range of different levels of cooling from solar geoengineering. Moore et al. (2015) used the relationship observed between sea surface temperatures and Atlantic hurricanes to evaluate the effects of solar geoengineering on storm surges along the east coast of North America.

In addition to these studies with models of reduced complexity, there have been a few studies employing glacier and ice sheet models. Irvine et al. (2009) conducted a study of the response of the Greenland Ice Sheet to a range of idealized and fixed scenarios of solar geoengineering deployment using the GLIMMER ice dynamics model driven by temperature and precipitation anomalies from a climate model and found that under an idealized scenario of quadrupled $\mathrm{CO}_{2}$ concentrations solar geoengineering could slow and even prevent the collapse of the ice sheet. Applegate and Keller (2015) used a simplified ice dynamics model driven by an Earth system model of intermediate complexity to evaluate the response of the Greenland Ice Sheet to scenarios of future GHG emissions and solar geoengineering deployment. They found that whilst solar geoengineering could slow or halt melting, there is strong hysteresis and restoring temperatures would not lead to a rapid recovery of the ice sheet. Zhao et al. (2017) evaluate the response of the 94000 high-mountain Asia glaciers using an empirical model based on each glacier's median elevation sensitivity to changes in only temperature and precipitation. Under scenarios in which solar geoengineering halts regional temperature increases, $30 \%$ of present-day glaciated area will still be lost this century due to the glaciers being out of balance with present-day climate.

These studies illustrate that if solar geoengineering were deployed it could reduce the rate of sea level rise substantially compared with greenhouse forcing alone. However, all studies to date have employed simplified global models. Thus these studies miss out on some of the fundamental differences between scenarios of climate change with and without solar geoengineering.

Whilst increasing the planetary albedo would undoubtedly cool the climate, the effects of a reduction in incoming light differ substantially from the heat-trapping effects of GHG forcing. GHG forcing acts more or less uniformly, whereas solar forcing acts only when the sun is up. Offsetting the GHG forcing with solar forcing would therefore produce seasonal, diurnal, and latitudinal differences in radiative forcing.

Furthermore, solar forcing acts primarily on the surface whereas GHG forcing acts most strongly on the middle troposphere where infrared radiation escapes to space. As a result, solar forcing reduces the intensity of the hydrological cycle more strongly than a reduction in GHG forcing that produces the same top-of-the-atmosphere radiative forcing. Bala et al. (2008) evaluated the sensitivity of the global hydrological cycle, finding a $2.4 \% \mathrm{~K}^{-1}$ change in global mean precipitation for solar forcing and only a $1.5 \% \mathrm{~K}^{-1}$ for $\mathrm{CO}_{2}$ forcing. They note that insolation changes result in relatively larger changes in net radiative fluxes at the surface than $\mathrm{CO}_{2}$ forcing, resulting in larger changes in sensible and latent heat fluxes.

Beyond this fundamental difference in the climate response to solar forcing, some stratospheric aerosols, particularly sulfuric acid, the most important single proposal, have significant near-infrared absorption bands that would result in a warming of the stratosphere. This warming would have dynamic implications, for example McCusker et al. (2015) find significant changes in circulation in the Antarctic stratosphere, which propagates down to affect surface winds and the mixing of waters around Antarctica.

These differences between GHG and shortwave forcing matter for making predictions of the surface mass balance of glaciers and ice sheets: melting of ice peaks during the day in summer when it is most sensitive to changes in surface energy balance, changes in snowfall amount, and seasonality would affect glacier mass balance, and solar geoengineering would alter atmospheric and oceanic circulation patterns, which can affect the upwelling of warm waters around ice shelves, weakening them. In the following sections we will identify how solar geoengineering could affect these factors and identify the most pressing uncertainties.

\section{Response of sea level rise to solar geoengineering}

In this section we evaluate the potential effects of solar geoengineering on the various contributions to sea level rise, addressing thermosteric sea level rise, surface mass balance, and ice shelf collapse and dynamic mass loss. In making this evaluation we aim to bring to light to two overarching questions. 
- How effective is solar geoengineering at reducing a given contribution to sea level rise compared to a reduction in GHG forcing that produced the same globalaverage change in temperature? Would, for example, $1{ }^{\circ} \mathrm{C}$ of global average cooling from solar geoengineering lower the surface-mass-balance contribution to sea level rise by more or less than $1{ }^{\circ} \mathrm{C}$ of cooling achieved by reduced GHG forcing?

- What fundamental limits are there to the potential for solar geoengineering to reduce or reverse sea level rise? That is, in what ways do the contributions to sea level rise exhibit hysteresis or tipping points that would make halting or reversing sea level rise with solar geoengineering more difficult than may be expected?

\subsection{Thermosteric sea level rise}

Global thermosteric sea level rise is the simplest contribution to global sea level rise. Thermosteric sea level can be computed from the density profile over depth, which is derived from temperature and salinity data (Dangendorf et al., 2014). Changes in temperature dominate steric sea level variability. A reduction in total radiative forcing, no matter if it comes from a reduction in GHG forcing or from solar geoengineering, will produce the same reduction in heat transfer to the ocean and so the same reduction in thermosteric sea level rise.

Bouttes et al. (2012) explore the reversibility of thermosteric sea level rise using a coupled climate model for a range of $\mathrm{CO}_{2}$ ramp-up and ramp-down scenarios, though the results apply equally to the case of solar geoengineering. They find that the thermosteric sea level rise response to their scenarios can be roughly approximated by the integral of radiative forcing, which closely corresponds to the total heat uptake of the oceans over the simulations. This implies that to halt thermosteric sea level rise, radiative forcing would need to be restored to preindustrial conditions. As the total forcing is ramped down, the warmed oceans become out of equilibrium with the now-cooled atmosphere and slowly give off the heat they absorbed, gradually reversing the thermosteric sea level rise that had occurred during the ramp-up (see Fig. 1 of Bouttes et al., 2012).

\subsection{Surface mass balance}

Many ice sheet and glacier models use a simple parameterization of surface mass balance, using a positive degree-day factor to estimate the amount of melt per degree above freezing at the glacier surface (Ohmura, 2001). Degree-day factors are determined empirically and vary due to surface albedo, meaning that a weathered ice surface such as the Greenland ice margin is rather dark and has high degree-day factors, while pristine snow cover has a low factor. This degree-day approach has been used in all studies of solar geoengineer- ing's effect on surface mass balance to date but it has some important limitations.

Fundamentally the surface melt rate depends on the availability of energy at the surface; this means that net shortwave radiation, net longwave radiation, sensible heat, and latent heat fluxes all matter. Despite only accounting for temperature, degree-day approaches generally produce results similar to more complete energy balance models for surface melt; this is because downwelling longwave radiation, which typically is the dominant contributor to the energy flux, correlates well with surface air temperature since much of the downwelling longwave radiation is emitted in the first $1 \mathrm{~km}$ of the atmosphere (Ohmura, 2001). However, degreeday approaches cannot capture the full response to changes in energy fluxes and a look at some case studies reveals that changes in insolation can have outsized impacts which will be underestimated by degree-day approaches.

Increased summer insolation at high latitudes during the Eemian interglacial period (115-130 kyr BP) raised temperatures but also directly affected surface melt. Van de Berg et al. (2011) made an attempt to separate the contributions of elevated temperatures and increased solar forcing and suggested that $45 \%$ of the change in surface mass balance could be attributed to the changed solar forcing alone.

Volcanic eruptions provide a more contemporary analogy to the potential effects of solar geoengineering on surface melt. Fettweis et al. (2007) simulated the surface mass balance of Greenland between 1979 and 2006 and find maxima for surface mass balance in 1983 and 1992, the years after the El Chichón and Pinatubo eruptions, respectively. Hanna et al. (2008) combine observations and modeling to evaluate the surface mass balance of Greenland over a longer period, finding that the years following El Chichón and Pinatubo have the third lowest and the lowest runoff and the third and sixth greatest surface mass balance, respectively, between 1958 and 2006.

In an analysis of recent changes over Greenland, Hofer et al. (2017) found that the substantial reduction in cloud cover over Greenland in the past 2 decades is the likeliest cause for the accelerated mass loss from the ice sheet over this period. To arrive at this result they simply calculated how much melt would result from the change in downward surface shortwave energy received over the melt season as a result of the change in cloud cover and compared this against the other contributions to melt and accumulation. They find that the $\sim 10 \%$ reduction in summer cloud cover over Greenland in the past 2 decades led to a $\sim 4000 \mathrm{Gt}$ loss of mass making it the dominant driver of surface mass balance change in this period. In Svalbard the opposite has been seen, with less melt than projected by degree-day models of glacier mass balance due to an increase in cloud cover partially offsetting the increased temperatures (Slangen et al., 2017). Giesen and Oerlemans (2012) and Lang et al. (2015) use glacier mass balance models that account for this change in surface shortwave radiation and produce a better fit to observations. 
These examples suggest that solar geoengineering could be more effective at changing surface melt than achieving the same reduction in temperature with a reduction in GHG forcing. To evaluate the differences in the drivers of surface mass balance, we conduct a simple analysis of the well-studied GeoMIP G1 experiment, in which the radiative forcing from an instantaneous quadrupling of $\mathrm{CO}_{2}$ concentrations is offset by a reduction in the solar constant sufficient to restore the preindustrial radiative balance and global-mean temperature (Kravitz et al., 2011). Kravitz et al. (2013) provide an overview of the climate response to this experiment from 12 Earth system models, and we analyze data for these same 12 models.

The models that ran the GeoMIP G1 experiment did not perfectly restore global-mean temperatures to the preindustrial levels, although the differences in top-of-atmosphere radiative forcing were specified to be less than $0.1 \mathrm{~W} \mathrm{~m}^{-2}$. As we are interested in the relative efficacy of solar geoengineering compared to an equivalent reduction in $\mathrm{CO}_{2}$ forcing, it is necessary to rescale these results so that they match the models' preindustrial global-mean temperature.

$$
F=\frac{\left(\mathrm{GMT}_{4 \times \mathrm{CO}_{2}}-\mathrm{GMT}_{\text {control }}\right)}{\left(\mathrm{GMT}_{4 \times \mathrm{CO}_{2}}-\mathrm{GMT}_{\mathrm{G} 1}\right)}
$$

where $F$ is the ratio between the global-mean temperature (GMT) anomaly of $4 \times \mathrm{CO}_{2}-$ control and of $4 \times$ $\mathrm{CO}_{2}-\mathrm{G} 1$. This ratio is greater than 1 if $\mathrm{G} 1$ is warmer than the control and less than 1 if it is cooler than the control. This ratio can then be used to rescale the effects of the reduction in solar constant to produce a synthetic scenario $\mathrm{G} 1^{*}$ in which global-mean temperatures would be identical to the control case:

$$
X_{\mathrm{G} 1 *}=X_{4 \times \mathrm{CO}_{2}}+F \times\left(X_{\mathrm{G} 1}-X_{4 \times \mathrm{CO}_{2}}\right),
$$

where $X$ is the variable to be rescaled. We apply this equation to all variables in our analysis. We also generate scenarios in which regional, annual-mean temperatures are restored using the same approach (G1-Greenland and G1-Antarctica).

Figures 1 and 2 compare the regional-mean anomalies from the control for the $4 \times \mathrm{CO}_{2}, \mathrm{G}^{*}$, and G1-local experiments and the efficacy of $\mathrm{G}^{*}$ and $\mathrm{G} 1$-local at offsetting $4 \times \mathrm{CO}_{2}$ trends for Greenland and Antarctica, respectively. Efficacy is defined as the fraction of the $4 \times \mathrm{CO}_{2}$ trend offset:

$E=\frac{X_{4 \times \mathrm{CO}_{2}}-X_{\mathrm{Geo}}}{X_{4 \times \mathrm{CO}_{2}}-X_{\text {control }}} \times 100 \%$.

As an example, many studies have shown that solar geoengineering is more effective at offsetting global-mean precipitation than global-mean temperature. Tilmes et al. (2013) find that compared to the control the GeoMIP ensemble mean showed a $6.9 \%$ increase in global-mean precipitation in $4 \times \mathrm{CO}_{2}$ and a $4.5 \%$ reduction in G1. Taking these numbers we find an efficacy of $165 \%$; that is, whilst $100 \%$ of the global-mean temperature response has been offset, $165 \%$ of the global precipitation response has been offset. When comparing the global-mean temperature and local-mean temperature efficacies, we find if $100 \%$ of the global-mean temperature has been offset, $90 \%$ of the Greenland mean temperature has been offset ( $90 \%$ efficacy relative to global temperature) and if $100 \%$ of the Greenland-mean temperature has been offset $111 \%$ of the global-mean temperature has been offset ( $111 \%$ efficacy relative to local temperature).

In Greenland (Fig. 1), G1* offsets most of the effects of $4 \times \mathrm{CO}_{2}$, bringing climate much closer to the control conditions with a median efficacy that is within $10 \%$ of $100 \%$. However, this result is a combination of $\mathrm{G} 1^{*}$ being undereffective at offsetting local temperatures, offsetting $90 \%$ of the annual mean and $91 \%$ of the summer mean, and being over-effective at offsetting the other fields relative to local temperatures, as seen in G1-Greenland results. There is a wide range of annual-mean precipitation responses across the ensemble in $\mathrm{G}^{*}$ but the ensemble median is close to $100 \%$, i.e., the substantial increase in precipitation in $4 \times \mathrm{CO}_{2}$ has been offset. The global-mean hydrological cycle has been weakened substantially but it seems local temperatures have been the dominant driver of the local hydrological response. The ensemble median shows a large increase in net downward surface radiation and surface heat flux of greater than $10 \mathrm{~W} \mathrm{~m}^{-2}$ for the $4 \times \mathrm{CO}_{2}$-control anomaly, though some models show considerably larger changes. Relative to local temperature change, solar geoengineering is over-effective at offsetting these changes in all models, with the ensemble median offsetting $116 \%$ of the net downward surface radiation and $111 \%$ of the net downward surface heat flux increases that were seen in $4 \times \mathrm{CO}_{2}$. These results suggest that positive degree-day melt schemes which do not account for these radiation and energy flux changes could underestimate the effectiveness of solar geoengineering at offsetting melt in Greenland by approximately $10 \%$.

In Antarctica (Fig. 2), a similar picture emerges as for Greenland with $\mathrm{G} 1^{*}$ being under-effective at offsetting local temperatures but relative to local temperature change being over-effective at offsetting the other fields. However, the implications of these results are different as melt plays only a small role in Antarctic surface mass balance, with accumulation dominating and with the surface mass balance contribution of Antarctica to future sea level rise projected to remain negative for the foreseeable future. Ligtenberg et al. (2013) predict an increase in Antarctic surface mass balance of $98 \mathrm{Gt} \mathrm{yr}^{-1} \mathrm{~K}^{-1}$ using the RACMO2 model and Lenaerts et al. (2016) predict an increase of $70 \mathrm{Gt} \mathrm{yr}^{-1} \mathrm{~K}^{-1}$ using the CESM model. The ensemble median precipitation response is close to control values in the $\mathrm{G} 1^{*}$ experiment, though there is substantial model spread, which suggests that regional temperatures dominate the Antarctic hydrological response rather than the state of the global hydrological cycle, which is significantly weaker in G1*. These results suggest that the negative contribution to sea level rise of the pos- 


\begin{tabular}{|lll|}
\multicolumn{3}{c}{ Greenland } \\
\hline MIROC-ESM & MPI-ESM-LR & NorESM1-M \\
HadCM3 & HadGEM2-ES & IPSL-CM5A-LR \\
CSIRO-MK3L-1-2 & CanESM2 & GISS-E2-R \\
BNU-ESM & CCSM4 & CESM-CAM5.1-FV \\
\hline
\end{tabular}
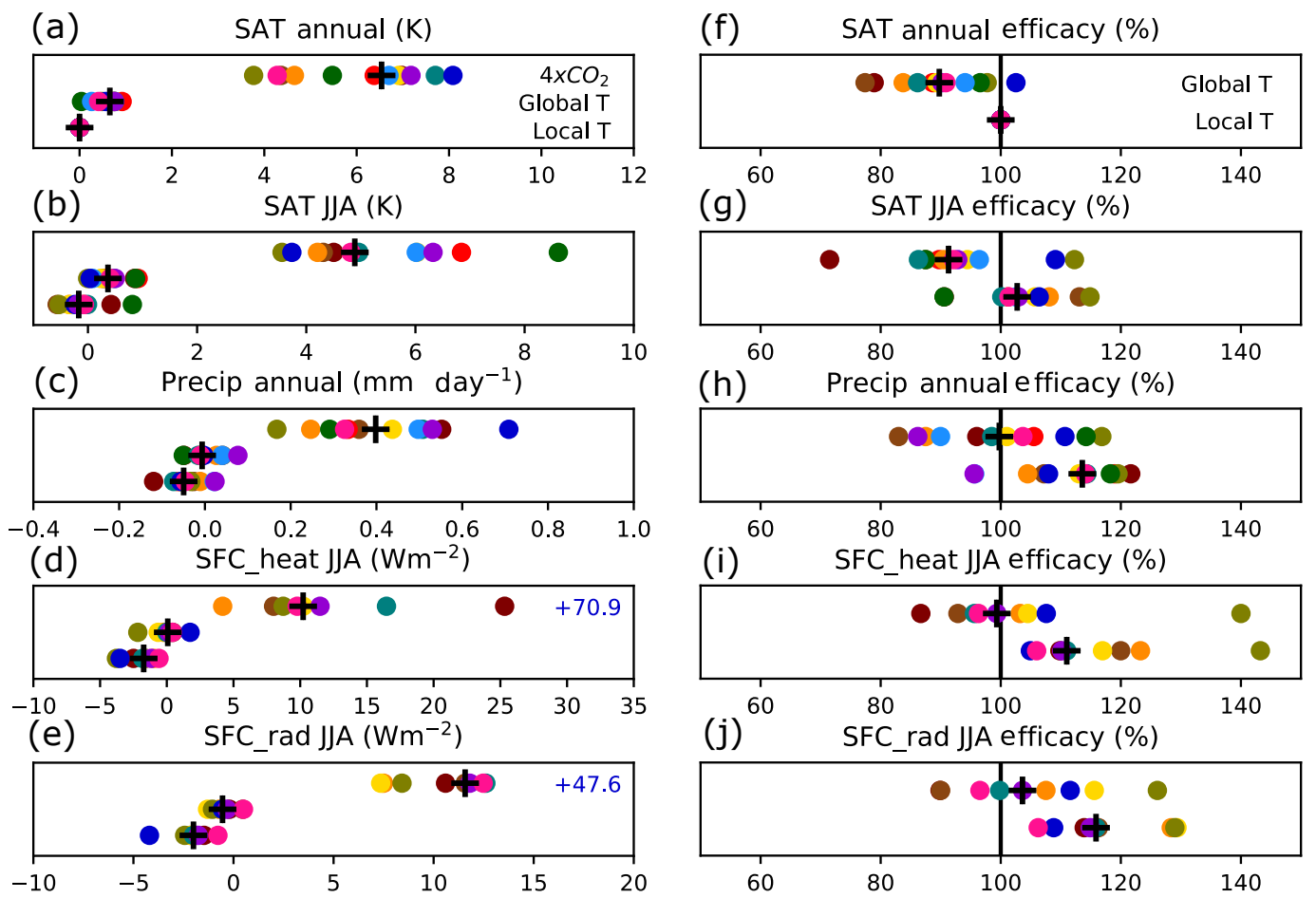

Figure 1. Regional-mean anomalies (a-e) and efficacies (f-j) of G1* and G1-Greenland at offsetting $4 \times \mathrm{CO}_{2}-\mathrm{control}^{*}$ regional-mean anomalies for Greenland for each model within the GeoMIP G1 ensemble. In (a-e), the upper points show the $4 \times \mathrm{CO}_{2}-$ control anomaly, the middle row of points show the G1* results, which restore global mean temperature, and the lower points show the results for G1Greenland, which restores local temperature. The ensemble median is shown with a plus symbol. The results from some outlier points have been displayed as text in the color of the corresponding model. SFC_heat is the net heat flux into the surface, i.e., net SW + net LW - sensible heat - latent heat, and SFC_rad is the net radiative flux into the surface, i.e., net SW + net LW. Efficacy is defined in the text. Where data were unavailable these models have not been plotted for those variables.

itive surface mass balance response of Antarctica to global warming would decline roughly in line with temperatures if solar geoengineering were deployed, though more work is needed to explore this issue.

This simple assessment supports the view that solar geoengineering would have a greater potential to reduce surface melt, and hence the sea level rise contribution from surface mass balance changes of glaciers and the ice sheets, than previous studies have suggested. However, several factors would need to be accounted for in future work to make a robust estimate of the efficacy of solar geoengineering at offsetting surface melt. First, the impacts of a reduction in incoming sunlight will be greater where the albedo of ice is lowest. A large and growing fraction of the ablation zone of Greenland in summer is darkened by distributed surface impurities and snow algae revealed when the snow layer is melted; these darkened areas typically have an albedo half that of clean ice (Ryan et al., 2018). The impact of reduced sunlight will also be greater in low-latitude regions where the shortwave flux makes up a greater fraction of the total contribution to the surface energy flux, e.g., in high-mountain Asia. For tropical and midlatitude glaciers, changes in accumulation due to changes in precipitation will also be an important factor to consider.

The results described here apply to a uniform reduction in incoming sunlight but the response to other more realistic forms of solar geoengineering could be tailored to produce different outcomes. For example, whilst a uniform reduction in incoming sunlight would not offset all warming at high latitudes, stratospheric aerosol geoengineering could be deployed to produce a thicker aerosol cloud at high latitudes to reduce high-latitude temperatures in line with global mean temperatures or to cool them further (Dai et al., 2018; Kravitz et al., 2018). However, it is important to note that the effects of solar geoengineering cannot be limited to the area of application and there would be remote impacts even if strato- 


\begin{tabular}{|lll|}
\multicolumn{3}{c}{ Antarctica } \\
\hline MIROC-ESM & MPI-ESM-LR & NorESM1-M \\
HadCM3 & HadGEM2-ES & IPSL-CM5A-LR \\
CSIRO-MK3L-1-2 & CanESM2 & GISS-E2-R \\
BNU-ESM & CCSM4 & CESM-CAM5.1-FV \\
\hline
\end{tabular}

(a) SAT annual (K)

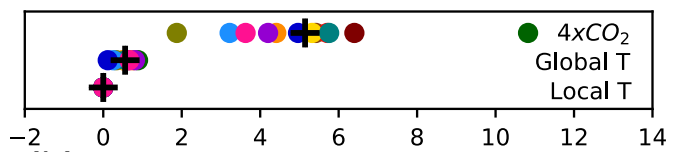

(b) $\quad 2 \quad 4$ SAT DJF (K)

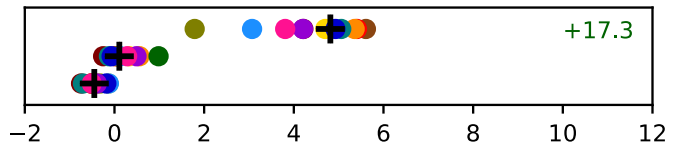

(c) Precip annual $\left(\mathrm{mm} \mathrm{day}{ }^{-1}\right)$

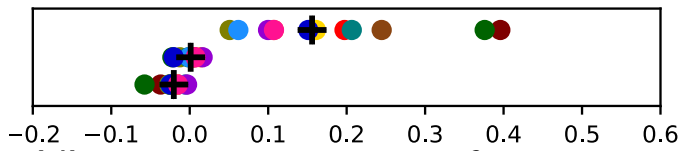

(d)

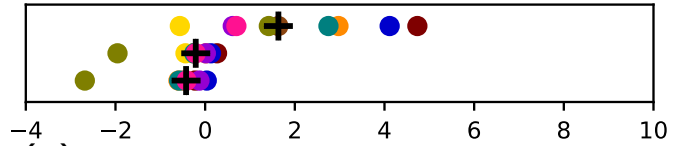

(e) ${ }^{-2} \quad \mathrm{SFC}_{-} \mathrm{rad}_{\mathrm{DJF}} \stackrel{4}{\left(\mathrm{Wm}^{-2}\right)}$

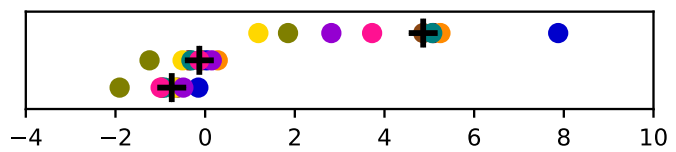

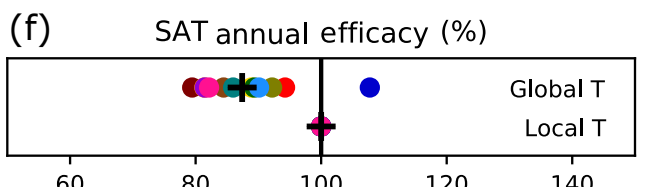

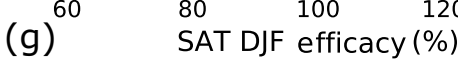
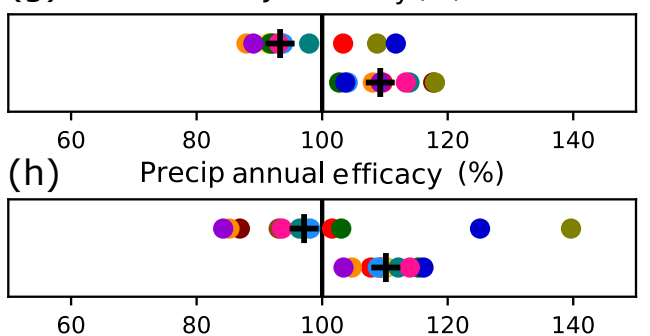

(i) SFC_heat DJF efficacy (\%)
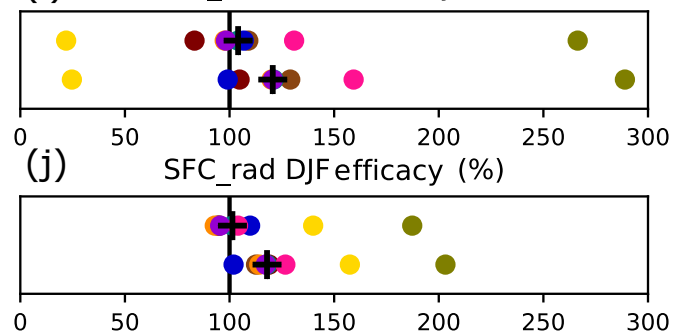

Figure 2. As in Fig. 1 but for Antarctica and Antarctic summer.

spheric aerosol geoengineering was limited just to polar regions (Robock et al., 2008).

\subsection{Ice shelf collapse and dynamic mass loss}

The other mechanism by which ice sheets lose mass is by calving icebergs from marine-terminating glaciers and here the effects of solar geoengineering are harder to anticipate. The rate of discharge depends on how fast the ice flows across the grounding line. The rate of ice flow depends on several factors that are affected by changes in climate. Warmer ice is less viscous, allowing it to flow faster, though this changes only very slowly and is negligible for the ice sheets on centennial timescales (Slangen et al., 2017). Increased meltwater can penetrate to the bed of the glacier and lubricate it, which may speed up the flow, although this "Zwally effect" seems not especially important in Greenland where surface meltwaters are efficiently drained in channelized drainage systems such that changes in surface runoff have little impact on basal friction (de Fleurian et al., 2016), and in Antarctica surface melt is not as of yet significant in fast-flowing glaciers (Joughin et al., 2009). For Antarctica where ice discharge is the dominant loss mechanism, the most significant effect of climate change is to thin and weaken ice shelves which provide a buttressing effect, pushing back against the glaciers and slowing their flow into the ocean.

Antarctica is so cold that little surface melt occurs on the ice shelves; however, relatively warm waters have been observed penetrating below the ice shelves, melting them from below (Pritchard et al., 2012). The water mass responsible for this melt is not the surface water around Antarctica but rather the circumpolar deep waters (originating around $500 \mathrm{~m}$ below the surface) that surround Antarctica. Surface winds have acted to pump this relatively warm circumpolar deep water up and into the ice shelf cavities. Here this relatively warm water can reach the grounding line where the ice starts to float and where pressure requires the ice to have the lowest melting point temperature. This ocean-driven melt has been observed to be thinning ice shelves, at rates as large as $50 \mathrm{~m}$ per year at the grounding line and as high as $14 \mathrm{~m}$ per year averaged over some of the larger ice shelves (Rintoul et al., 2016), weakening their buttressing effect and increasing the rate of discharge of glaciers into the ocean (Favier et al., 2014). It is generally believed that the fate of the ice shelves is likely to be determined by the degree to which this circumpolar deep water is able to penetrate into the deep ice 
shelf cavities rather than by surface melt (Liu et al., 2015; Pritchard et al., 2012).

A recent study (DeConto and Pollard, 2016) has challenged this view, suggesting that the atmospheric warming that led to the breakup of some Antarctic Peninsula ice shelves would, if the warming continued, destabilize the larger southern ice shelves in the future. The process is through the hydrostatic head of meltwater-filled crevasses, which results in "hydrofracture" and the rapid disintegration of the ice shelf (Scambos et al., 2013). Furthermore, they suggest that once large ice shelves begin to retreat, the large unstable ice cliffs formed could promote further rapid retreat, in a process dubbed marine ice cliff instability (Pollard et al., 2015). Together these processes combined to produce a substantially greater Antarctic contribution to sea level rise than seen in earlier studies which did not account for these highly uncertain processes (DeConto and Pollard, 2016).

Climate change and solar geoengineering will affect the ice shelves, and hence the rate of discharge of marine glaciers, primarily by changing surface air temperature and wind patterns that affect the upwelling of circumpolar deep water. Solar geoengineering could lower surface air temperatures and hence reduce the likelihood of surface-meltinduced hydrofracturing of the ice shelves as assessed by DeConto and Pollard (2016). Whilst solar geoengineering could lower surface air temperatures and surface ocean temperatures around Antarctica, this would have a limited impact on the temperature of the deep circumpolar water mass responsible for thinning the ice shelves in the near future as it is deep below the surface. As noted above, ocean-driven melt is primarily controlled by the upwelling of these deep waters, which is driven by Southern Ocean winds. A recent study of the effects of stratospheric sulfate aerosol geoengineering in a scenario of future GHG emissions found that it would warm the stratosphere, changing both atmospheric and oceanic circulation patterns (McCusker et al., 2015). They simulated a greater upwelling of circumpolar deep water relative to a scenario without an increase in GHG forcing but that ocean temperatures were significantly lower than in the GHG-forcing-only scenario. If this result proves robust, then it suggests that whilst stratospheric aerosol geoengineering or at least geoengineering using aerosols like sulfates, which strongly alter stratospheric heating rates - could lower surface melt considerably it may have a limited ability to reduce ice shelf basal melt rates.

The dynamical response of marine glacier ice flow to changes in the buttressing effect of ice shelves is not simple and there is the potential for runaway responses which would limit solar geoengineering's potential to slow or reverse this contribution to sea level rise. Fürst et al. (2016) show that ice shelves in the West Antarctic Amundsen and Bellingshausen seas are extremely sensitive to calving, meaning that even a small amount of increased calving will trigger dynamical responses in the feeding ice streams, increasing their flow rate. Furthermore, West Antarctica's geography makes its ice sheet especially vulnerable to such changes. Much of the ice sheet rests on bedrock below sea level, which becomes deeper further from the coast. This arrangement makes many of Antarctica's glaciers susceptible to "marine ice sheet instability" (Mercer, 1978), in that if the boundary layer begins to retreat, the ice flow across the grounding line increases, prompting a self-sustaining retreat that would continue until a bedrock ridge further inland. In fact, observations suggest that recent increases in the temperature of water around Antarctica may have already triggered a process that will lead to the collapse of the Pine Island and Thwaites glaciers (Favier et al., 2014; Joughin et al., 2014). Unless an ice stream has exceptionally strong lateral buttressing (Robel et al., 2016), a marine ice sheet instability, once started, may only be stopped by modifying bathymetry to provide extra buttressing, as simulated by flow-band modeling on Thwaites Glacier (Wolovick and Moore, 2018). However, initial results from the BISICLES model evaluating the response of an idealized vulnerable marine glacier to imposed warming found that returning the entire water column to cooler conditions reversed the retreat that had begun during the warming (Asay-Davis et al., 2016). It seems reasonable to expect that solar geoengineering, like emissions cuts, may help to prevent other marine glaciers from becoming unstable by limiting surface melt that could lead to ice shelf collapse but would have a limited ability to reverse subsurface warming on decadal timescales. It may be that significant losses from some West Antarctic glaciers are unavoidable by simply returning climate and oceanic driving conditions to the preindustrial conditions and perhaps that even doing so would not be sufficient to arrest the retreat.

\section{Recommendations for research}

In this study we have reviewed the literature on the effects of solar geoengineering on sea level rise and highlighted several gaps and shortcomings in the approaches used to date. We have also highlighted important differences between a reduction in GHG forcing and solar geoengineering that will affect the surface mass balance of glaciers and ocean-driven melt of ice shelves and thus the discharge rate of marine glaciers. We conclude with specific research recommendations that will help to address the key questions we have highlighted earlier: would solar geoengineering be more, or less, effective at offsetting sea level rise than an equivalent reduction in GHG forcing? And what are the limits to solar geoengineering's potential to reduce or reverse sea level rise?

\subsection{Evaluate the sea level rise response to scenarios of solar geoengineering deployment alongside other scenarios of future climate change}

Many of the new Earth system models taking part in CMIP6 include coupled ice sheet model components and are ideal for 
making an initial assessment of the questions we have raised. The Ice Sheet Model Intercomparison Project phase 6 (ISMIP6) aims to evaluate the ice sheet response of coupled ice sheet models to idealized and future emissions scenarios (Goelzer et al., 2018). The future emission scenario chosen by this project is the business-as-usual SSP5-8.5 scenario (which reaches $8.5 \mathrm{~W} \mathrm{~m}^{-2}$ by 2100), which is also the basis for the GeoMIP6 G6 experiment in which the radiative forcing is reduced to match the SSP4- 6.0 scenario $\left(6.0 \mathrm{~W} \mathrm{~m}^{-2}\right.$ by 2100 ) out to 2100 . We recommend that groups participating in both ISMIP6 and GeoMIP6 take this opportunity to extend the ISMIP6 protocol to the GeoMIP G6 experiment, i.e., producing a run including the coupled ice sheet model and running an offline ice sheet model, to explore the effects of solar geoengineering on sea level. To evaluate the relative efficacy of solar geoengineering, these results could be compared to the coupled ice sheet model response to the SSP46.0 scenario, which has a reduction in GHG forcing equivalent to that offset by stratospheric aerosol geoengineering in GeoMIP6 G6.

Insight into the limits of solar geoengineering as a means to reduce sea level rise can also be gained by extending the idealized simulations studied in ISMIP6. ISMIP6 also focuses on an idealized simulation in which $\mathrm{CO}_{2}$ concentrations rise at $1 \%$ per year until $4 \times \mathrm{CO}_{2}$ is reached (after 140 years); we recommend extending this protocol by fixing $\mathrm{CO}_{2}$ concentrations at $4 \times \mathrm{CO}_{2}$ values thereafter but also lowering the solar constant at such a rate that globalmean temperatures are restored to control conditions after 140 years. We note that CDR-MIP also includes a similar experiment which reduces $\mathrm{CO}_{2}$ concentrations at the same rate that they were raised and would be an interesting target for study (Keller et al., 2018). These idealized ramp-up, rampdown scenarios would provide a solid basis for evaluating the potential of solar geoengineering, and carbon dioxide removal, to reverse sea level rise, showing the extent to which hysteresis and threshold behaviors would limit this potential. Furthermore, a comparison between the solar constant and $\mathrm{CO}_{2}$ ramp-down scenarios would allow an evaluation of whether solar geoengineering would be more or less effective at reversing sea level rise.

\subsection{Evaluate the surface mass balance response to solar geoengineering using dedicated regional surface mass balance models}

As we show above, there are good theoretical reasons and now some limited model evidence to support the view that solar geoengineering would be more effective than an equivalent reduction in GHG forcing. However, there are several unknowns that preclude making any quantitative statements about this effect. For example, the steep orography of the ablation zone will not be well captured in coarse models, changes in surface albedo due to impurities may not be well captured, and regional biases in climate can have a significant impact on results. We therefore recommend that the analysis of the coupled ice sheet models recommended above be complemented by simulations with dedicated regional surface mass balance models. As noted above, a comparison between the surface mass balance in the GeoMIP G6 and SSP46.0 scenarios would allow a quantification of the relative efficacy of solar geoengineering at offsetting the reduction in surface mass balance in a warmer world.

\subsection{Evaluate the effect of solar geoengineering on the upwelling of Antarctic Circumpolar Deep Water and on the stability of the ice shelves and marine glaciers}

The study of McCusker et al. (2015) suggests that stratospheric aerosol geoengineering may promote upwelling as changes in stratospheric circulation could propagate downwards to change surface winds around Antarctica. If this is the case, stratospheric aerosol geoengineering could be significantly less effective than a reduction in GHG forcing at offsetting the increased upwelling of circumpolar deep water around Antarctica. Future work should investigate whether this result is robust across the ensemble of models running the GeoMIP6 G6 stratospheric aerosol experiment. In addition, as the climate response to stratospheric aerosols depends strongly on the type of aerosol released and the distribution of the aerosols (Dykema et al., 2016), whether it may be possible to avoid unfavorable wind patterns by deploying stratospheric aerosol geoengineering differently should be explored in further climate model simulations.

\subsection{Evaluate sea level rise risks as part of an interdisciplinary evaluation of solar geoengineering}

Sea level rise is one of the key risks of climate change and so it will be important to understand the potential efficacy and the limits of solar geoengineering as a means to reduce sea level rise; however, sea level rise is only one of many issues that must be considered when discussing solar geoengineering. There are likely good reasons not to deploy solar geoengineering with the objective of halting or reversing sea level rise as this seems likely to require a substantial reduction in global temperatures, which could result in potentially harmful shifts in regional climate and significant nonclimatic side effects (Irvine et al., 2012). Furthermore, whilst an understanding of the potential physical consequences of climate change and solar geoengineering is necessary for a discussion of the potential use of solar geoengineering, it is not sufficient. Whether and how to deploy solar geoengineering is a question that demands a nuanced discussion encompassing not only the physical consequences of deployment but also a careful consideration and negotiation of the complex sociopolitical issues it raises. A good understanding of the potential and limits of solar geoengineering to reduce sea level rise will be an important part of the foundation of this 
much broader discussion in which we hope the cryosphere research community will engage.

Data availability. Model output from the geoengineering model intercomparison project and from the coupled model intercomparison project has been collated and processed and these data are available for download here: https://doi.org/10.7910/DVN/NUCBXU (Irvine et al., 2018).

Author contributions. All authors contributed to the writing of the paper. PI and JM conducted the literature review. Analysis and visualization were conducted by PI.

Competing interests. The authors declare that they have no conflict of interest.

Acknowledgements. We thank all participants of the Geoengineering Model Intercomparison Project and their model development teams, the scientists managing the Earth System Grid data nodes who assisted in making GeoMIP output available. We thank the two anonymous reviewers for their constructive comments. We acknowledge the World Climate Research Programme's Working Group on Coupled Modelling, which is responsible for CMIP. For CMIP, the U.S. Department of Energy's Program for Climate Model Diagnosis and Intercomparison provides coordinating support and led development of software infrastructure in partnership with the Global Organization for Earth System Science Portals.

Edited by: Xavier Fettweis

Reviewed by: two anonymous referees

\section{References}

Applegate, P. J. and Keller, K.: How effective is albedo modification (solar radiation management geoengineering) in preventing sealevel rise from the Greenland Ice Sheet?, Environ. Res. Lett., 10, 084018, https://doi.org/10.1088/1748-9326/10/8/084018, 2015.

Asay-Davis, X. S., Cornford, S. L., Durand, G., Galton-Fenzi, B. K., Gladstone, R. M., Gudmundsson, G. H., Hattermann, T., Holland, D. M., Holland, D., Holland, P. R., Martin, D. F., Mathiot, P., Pattyn, F., and Seroussi, H.: Experimental design for three interrelated marine ice sheet and ocean model intercomparison projects: MISMIP v.3 (MISMIP+), ISOMIP v.2 (ISOMIP +) and MISOMIP v.1 (MISOMIP1), Geosci. Model Dev., 9, 24712497, https://doi.org/10.5194/gmd-9-2471-2016, 2016.

Bala, G., Duffy, P. B., and Taylor, K. E.: Impact of geoengineering schemes on the global hydrological cycle, P. Natl. Acad. Sci. USA., 105, 7664-7669, https://doi.org/10.1073/pnas.0711648105, 2008.

Bamber, J. L. and Aspinall, W. P.: An expert judgement assessment of future sea level rise from the ice sheets, Nat. Clim. Change, 3, 424-427, https://doi.org/10.1038/nclimate1778, 2013.
Boucher, O., Randall, D., Artaxo, P., Bretherton, C., Feingold, G., Forster, P., Kerminen, V.-M., Kondo, Y., Liao, H., Lohmann, U., Rasch, P., Satheesh, S. K., Sherwood, S., Stevens, B., and Zhang, X. Y.: Clouds and Aerosols, in: Climate Change 2013: The Physical Science Basis, Contribution of Working Group I to the Fifth Assessment Report of the Intergovernmental Panel on Climate Change, edited by: Stocker, T. F., Qin, D., Plattner, G.-K., Tignor, M., Allen, S. K., Boschung, J., Nauels, A., Xia, Y., Bex, V., and Midgley, P. M., Cambridge University Press, Cambridge, UK and New York, NY, USA, 2013.

Bouttes, N., Gregory, J. M., and Lowe, J. A.: The Reversibility of Sea Level Rise, J. Climate, 26, 2502-2513, https://doi.org/10.1175/JCLI-D-12-00285.1, 2012.

Budyko, M. I.: Climatic Changes, Waverly Press, Baltimore, available at: http://books.google.nl/books?id=WZxn8IhIFf4C (last access: 31 May 2017), 1977.

Clark, P. U., Shakun, J. D., Marcott, S. A., Mix, A. C., Eby, M., Kulp, S., Levermann, A., Milne, G. A., Pfister, P. L., Santer, B. D., Schrag, D. P., Solomon, S., Stocker, T. F., Strauss, B. H., Weaver, A. J., Winkelmann, R., Archer, D., Bard, E., Goldner, A., Lambeck, K., Pierrehumbert, R. T., and Plattner, G.-K.: Consequences of twenty-first-century policy for multi-millennial climate and sea-level change, Nat. Clim. Change, 6, 360-369, https://doi.org/10.1038/nclimate2923, 2016.

Dai, Z., Weisenstein, D. K., and Keith, D. W.: Tailoring Meridional and Seasonal Radiative Forcing by Sulfate Aerosol Solar Geoengineering, Geophys. Res. Lett., 45, 1030-1039, https://doi.org/10.1002/2017GL076472, 2018.

Dangendorf, S., Calafat, F. M., Arns, A., Wahl, T., Haigh, I. D., and Jensen, J.: Mean sea level variability in the North Sea: Processes and implications, J. Geophys. Res.-Oceans, 119, 68206841, https://doi.org/10.1002/2014JC009901, 2014.

DeConto, R. M. and Pollard, D.: Contribution of Antarctica to past and future sea-level rise, Nature, 531, 591-597, https://doi.org/10.1038/nature17145, 2016.

de Fleurian, B., Morlighem, M., Seroussi, H., Rignot, E., van den Broeke, M. R., Munneke, P. K., Mouginot, J., Smeets, P. C. J. P., and Tedstone, A. J.: A modeling study of the effect of runoff variability on the effective pressure beneath Russell Glacier, West Greenland, J. Geophys. Res.-Ea. Surf., 121, 1834 1848, https://doi.org/10.1002/2016JF003842, 2016.

Dykema, J. A., Keith, D. W., and Keutsch, F. N.: Improved aerosol radiative properties as a foundation for solar geoengineering risk assessment, Geophys. Res. Lett., 43, 7758-7766, https://doi.org/10.1002/2016GL069258, 2016.

Favier, L., Durand, G., Cornford, S. L., Gudmundsson, G. H., Gagliardini, O., Gillet-Chaulet, F., Zwinger, T., Payne, A. J., and Le Brocq, A. M.: Retreat of Pine Island Glacier controlled by marine ice-sheet instability, Nat. Clim. Change, 4, 117-121, https://doi.org/10.1038/nclimate2094, 2014.

Fettweis, X.: Reconstruction of the 1979-2006 Greenland ice sheet surface mass balance using the regional climate model MAR, The Cryosphere, 1, 21-40, https://doi.org/10.5194/tc-1-21-2007, 2007.

Fürst, J. J., Durand, G., Gillet-Chaulet, F., Tavard, L., Rankl, M., Braun, M., and Gagliardini, O.: The safety band of Antarctic ice shelves, Nat. Clim. Change, 6, 479-482, https://doi.org/10.1038/nclimate2912, 2016. 
Giesen, R. H. and Oerlemans, J.: Calibration of a surface mass balance model for global-scale applications, The Cryosphere, 6, 1463-1481, https://doi.org/10.5194/tc-6-1463-2012, 2012.

Goelzer, H., Nowicki, S., Edwards, T., Beckley, M., Abe-Ouchi, A., Aschwanden, A., Calov, R., Gagliardini, O., Gillet-Chaulet, F., Golledge, N. R., Gregory, J., Greve, R., Humbert, A., Huybrechts, P., Kennedy, J. H., Larour, E., Lipscomb, W. H., Le clec'h, S., Lee, V., Morlighem, M., Pattyn, F., Payne, A. J., Rodehacke, C., Rückamp, M., Saito, F., Schlegel, N., Seroussi, H., Shepherd, A., Sun, S., van de Wal, R., and Ziemen, F. A.: Design and results of the ice sheet model initialisation experiments initMIP-Greenland: an ISMIP6 intercomparison, The Cryosphere, 12, 1433-1460, https://doi.org/10.5194/tc-12-14332018, 2018.

Hanna, E., Huybrechts, P., Steffen, K., Cappelen, J., Huff, R., Shuman, C., Irvine-Fynn, T., Wise, S., and Griffiths, M.: Increased Runoff from Melt from the Greenland Ice Sheet: A Response to Global Warming, J. Climate, 21, 331-341, https://doi.org/10.1175/2007JCLI1964.1, 2008.

Hinkel, J., Lincke, D., Vafeidis, A. T., Perrette, M., Nicholls, R. J., Tol, R. S. J., Marzeion, B., Fettweis, X., Ionescu, C., and Levermann, A.: Coastal flood damage and adaptation costs under 21st century sea-level rise, P. Natl. Acad. Sci. USA, 111, 32923297, https://doi.org/10.1073/pnas.1222469111, 2014.

Hofer, S., Tedstone, A. J., Fettweis, X., and Bamber, J. L.: Decreasing cloud cover drives the recent mass loss on the Greenland Ice Sheet, Sci. Adv., 3, e1700584, https://doi.org/10.1126/sciadv.1700584, 2017.

Irvine, P. J., Lunt, D. J., Stone, E. J., and Ridgwell, A. J.: The fate of the Greenland Ice Sheet in a geoengineered, high $\mathrm{CO}_{2}$ world, Environ. Res. Lett., 4, 045109, https://doi.org/10.1088/17489326/4/4/045109, 2009.

Irvine, P. J., Sriver, R. L., and Keller, K.: Tension between reducing sea-level rise and global warming through solar-radiation management, Nat. Clim. Change, 2, 97-100, https://doi.org/10.1038/nclimate1351, 2012.

Irvine, P. J., Kravitz, B., Lawrence, M. G., and Muri, H.: An overview of the Earth system science of solar geoengineering, Wiley Interdiscip. Rev. Clim. Change, 7, 815-833, https://doi.org/10.1002/wcc.423, 2016.

Irvine, P. J., Keith, D., and Moore, J.: GeoMIP Surface Mass Balance Data, Harvard Dataverse, https://doi.org/10.7910/DVN/ NUCBXU, 2018.

Jevrejeva, S., Jackson, L. P., Riva, R. E. M., Grinsted, A., and Moore, J. C.: Coastal sea level rise with warming above $2^{\circ}$ C, P. Natl. Acad. Sci. USA, 113, 13342-13347, https://doi.org/10.1073/pnas.1605312113, 2016.

Joughin, I., Tulaczyk, S., Bamber, J. L., Blankenship, D., Holt, J. W., Scambos, T., and Vaughan, D. G.: Basal conditions for Pine Island and Thwaites Glaciers, West Antarctica, determined using satellite and airborne data, J. Glaciol., 55, 245-257, https://doi.org/10.3189/002214309788608705, 2009.

Joughin, I., Smith, B. E., and Medley, B.: Marine Ice Sheet Collapse Potentially Under Way for the Thwaites Glacier Basin, West Antarctica, Science, 344, 735-738, https://doi.org/10.1126/science.1249055, 2014.

Keith, D. W. and Irvine, P. J.: Solar geoengineering could substantially reduce climate risks - A research hypothesis for the next decade: Solar Geoengineering Cloud Reduce Risk, Earths Future, 4, 549-559, https://doi.org/10.1002/2016EF000465, 2016.

Keith, D. W., Weisenstein, D. K., Dykema, J. A., and Keutsch, F. N.: Stratospheric solar geoengineering without ozone loss, P. Natl. Acad. Sci. USA, 113, 14910-14914, https://doi.org/10.1073/pnas.1615572113, 2016.

Keller, D. P., Lenton, A., Scott, V., Vaughan, N. E., Bauer, N., Ji, D., Jones, C. D., Kravitz, B., Muri, H., and Zickfeld, K.: The Carbon Dioxide Removal Model Intercomparison Project (CDRMIP): rationale and experimental protocol for CMIP6, Geosci. Model Dev., 11, 1133-1160, https://doi.org/10.5194/gmd-111133-2018, 2018.

Kopp, R. E., Horton, R. M., Little, C. M., Mitrovica, J. X., Oppenheimer, M., Rasmussen, D. J., Strauss, B. H., and Tebaldi, C.: Probabilistic 21st and 22nd century sea-level projections at a global network of tide-gauge sites, Earths Future, 2, 383-406, https://doi.org/10.1002/2014EF000239, 2014.

Kravitz, B., Robock, A., Boucher, O., Schmidt, H., Taylor, K. E., Stenchikov, G., and Schulz, M.: The Geoengineering Model Intercomparison Project (GeoMIP), Atmos. Sci. Lett., 12, 162167, https://doi.org/10.1002/asl.316, 2011.

Kravitz, B., MacMartin, D. G., and Caldeira, K.: Geoengineering: Whiter skies?, Geophys. Res. Lett., 39, L11801, https://doi.org/10.1029/2012g1051652, 2012.

Kravitz, B., Caldeira, K., Boucher, O., Robock, A., Rasch, P. J., Alterskjær, K., Bou Karam, D., Cole, J. N. S., Curry, C. L., Haywood, J. M., Irvine, P. J., Ji, D., Jones, A., Kristjánsson, J. E., Lunt, D. J., Moore, J. C., Niemeier, U., Schmidt, H., Schulz, M., Singh, B., Tilmes, S., Watanabe, S., Yang, S., and Yoon, J.-H.: Climate model response from the Geoengineering Model Intercomparison Project (GeoMIP), J. Geophys. Res.-Atmos., 118, 8320-8332, https://doi.org/10.1002/jgrd.50646, 2013.

Kravitz, B., MacMartin, D. G., Mills, M. J., Richter, J. H., Tilmes, S., Lamarque, J.-F., Tribbia, J. J., and Vitt, F.: First Simulations of Designing Stratospheric Sulfate Aerosol Geoengineering to Meet Multiple Simultaneous Climate Objectives, J. Geophys. Res.-Atmos., 122, 12616-12634, https://doi.org/10.1002/2017JD026874, 2018.

Lang, C., Fettweis, X., and Erpicum, M.: Stable climate and surface mass balance in Svalbard over 1979-2013 despite the Arctic warming, The Cryosphere, 9, 83-101, https://doi.org/10.5194/tc9-83-2015, 2015.

Latham, J.: Control of global warming, Nature, 347, 339-340, 1990.

Lenaerts, J. T. M., Vizcaino, M., Fyke, J., van Kampenhout, L., and van den Broeke, M. R.: Present-day and future Antarctic ice sheet climate and surface mass balance in the Community Earth System Model, Clim. Dynam., 47, 1367-1381, https://doi.org/10.1007/s00382-015-2907-4, 2016.

Ligtenberg, S. R. M., van de Berg, W. J., van den Broeke, M. R., Rae, J. G. L., and van Meijgaard, E.: Future surface mass balance of the Antarctic ice sheet and its influence on sea level change, simulated by a regional atmospheric climate model, Clim. Dynam., 41, 867-884, https://doi.org/10.1007/s00382-013-1749-1, 2013.

Liu, Y., Moore, J. C., Cheng, X., Gladstone, R. M., Bassis, J. N., Liu, H., Wen, J., and Hui, F.: Ocean-driven thinning enhances iceberg calving and retreat of Antarctic ice shelves, P. Natl. Acad. Sci. USA, 112, 3263-3268, https://doi.org/10.1073/pnas.1415137112, 2015. 
McClellan, J., Keith, D. W., and Apt, J.: Cost analysis of stratospheric albedo modification delivery systems, Environ. Res. Lett., 7, 034019, https://doi.org/10.1088/1748-9326/7/3/034019, 2012.

McCusker, K. E., Battisti, D. S., and Bitz, C. M.: Inability of stratospheric sulfate aerosol injections to preserve the West Antarctic Ice Sheet, Geophys. Res. Lett., 42, 4989-4997, https://doi.org/10.1002/2015GL064314, 2015.

Mercer, J. H.: West Antarctic ice sheet and $\mathrm{CO}_{2}$ greenhouse effect: a threat of disaster, Nature, 271, 321-325, https://doi.org/10.1038/271321a0, 1978.

Mitchell, D. L. and Finnegan, W.: Modification of cirrus clouds to reduce global warming, Environ. Res. Lett., 4, 045102, https://doi.org/10.1088/1748-9326/4/4/045102, 2009.

Moore, J. C., Jevrejeva, S., and Grinsted, A.: Efficacy of geoengineering to limit 21st century sea-level rise, P. Natl. Acad. Sci. USA, 107, 15699-15703, https://doi.org/10.1073/pnas.1008153107, 2010.

Moore, J. C., Grinsted, A., Guo, X., Yu, X., Jevrejeva, S., Rinke, A., Cui, X., Kravitz, B., Lenton, A., Watanabe, S., and Ji, D.: Atlantic hurricane surge response to geoengineering, P. Natl. Acad. Sci. USA, 112, 13794-13799, https://doi.org/10.1073/pnas.1510530112, 2015.

Moriyama, R., Sugiyama, M., Kurosawa, A., Masuda, K., Tsuzuki, K., and Ishimoto, Y.: The cost of stratospheric climate engineering revisited, Mitig. Adapt. Strateg. Glob. Change, 22, 12071228, https://doi.org/10.1007/s11027-016-9723-y, 2016.

Ohmura, A.: Physical Basis for the TemperatureBased Melt-Index Method, J. Appl. Meteorol., 40, 753-761, https://doi.org/10.1175/15200450(2001)040<0753:PBFTTB > 2.0.CO;2, 2001.

Oppenheimer, M., Little, C. M., and Cooke, R. M.: Expert judgement and uncertainty quantification for climate change, Nat. Clim. Change, 6, 445-451, https://doi.org/10.1038/nclimate2959, 2016.

Pitari, G., Aquila, V., Kravitz, B., Robock, A., Watanabe, S., Cionni, I., Luca, N. D., Genova, G. D., Mancini, E., and Tilmes, S.: Stratospheric ozone response to sulfate geoengineering: Results from the Geoengineering Model Intercomparison Project (GeoMIP), J. Geophys. Res.-Atmos., 119, 2629-2653, https://doi.org/10.1002/2013JD020566, 2014.

Pollard, D., DeConto, R. M., and Alley, R. B.: Potential Antarctic Ice Sheet retreat driven by hydrofracturing and ice cliff failure, Earth Planet. Sc. Lett., 412, 112-121, https://doi.org/10.1016/j.epsl.2014.12.035, 2015.

Pritchard, H. D., Ligtenberg, S. R. M., Fricker, H. A., Vaughan, D. G., van den Broeke, M. R., and Padman, L.: Antarctic ice-sheet loss driven by basal melting of ice shelves, Nature, 484, 502-505, https://doi.org/10.1038/nature10968, 2012.

Rintoul, S. R., Silvano, A., Pena-Molino, B., van Wijk, E., Rosenberg, M., Greenbaum, J. S., and Blankenship, D. D.: Ocean heat drives rapid basal melt of the Totten Ice Shelf, Sci. Adv., 2, e1601610, https://doi.org/10.1126/sciadv.1601610, 2016.

Ritz, C., Edwards, T. L., Durand, G., Payne, A. J., Peyaud, V., and Hindmarsh, R. C. A.: Potential sea-level rise from Antarctic icesheet instability constrained by observations, Nature, 528, 115118, https://doi.org/10.1038/nature16147, 2015.

Robel, A. A., Schoof, C., and Tziperman, E.: Persistence and variability of ice-stream grounding lines on retrograde bed slopes,
The Cryosphere, 10, 1883-1896, https://doi.org/10.5194/tc-101883-2016, 2016.

Robock, A., Oman, L., and Stenchikov, G. L.: Regional climate responses to geoengineering with tropical and Arctic $\mathrm{SO}_{2}$ injections, J. Geophys. Res.-Atmos., 113, D16101, https://doi.org/10.1029/2008jd010050, 2008.

Robock, A., Marquardt, A., Kravitz, B., and Stenchikov, G.: Benefits, risks, and costs of stratospheric geoengineering, Geophys. Res. Lett., 36, L19703, https://doi.org/10.1029/2009g1039209, 2009.

Ryan, J. C., Hubbard, A., Stibal, M., Irvine-Fynn, T. D., Cook, J., Smith, L. C., Cameron, K., and Box, J.: Dark zone of the Greenland Ice Sheet controlled by distributed biologically-active impurities, Nat. Commun., 9, 1065, https://doi.org/10.1038/s41467018-03353-2, 2018.

Scambos, T., Hulbe, C., and Fahnestock, M.: Climate-Induced Ice Shelf Disintegration in the Antarctic Peninsula, in: Antarctic Peninsula Climate Variability: Historical and Paleoenvironmental Perspectives, edited by: Domack, E.,Levente, A., Burnet, A., Bindschadler, R., Convey, P., and Kirby, M., https://doi.org/10.1029/AR079p0079, 2013.

Shepherd, J., Caldeira, K., Cox, P., Haigh, J., Keith, D., Launder, B., Mace, G., MacKerron, G., Pyle, J., Rayner, S., Redgwell, C., Watson, A., Garthwaite, R., Heap, R., Parker, A., and Wilsdon, J.: Geoengineering the climate: science, governace and uncertainty, The Royal Society, London, 2009.

Slangen, A. B. A., Adloff, F., Jevrejeva, S., Leclercq, P. W., Marzeion, B., Wada, Y., and Winkelmann, R.: A Review of Recent Updates of Sea-Level Projections at Global and Regional Scales, Surv. Geophys., 38, 385-406, https://doi.org/10.1007/s10712-016-9374-2, 2017.

Tilmes, S., Garcia, R. R., Kinnison, D. E., Gettelman, A., and Rasch, P. J.: Impact of geoengineered aerosols on the troposphere and stratosphere, J. Geophys. Res.-Atmos., 114, D12305, https://doi.org/10.1029/2008jd011420, 2009.

Tilmes, S., Kinnison, D. E., Garcia, R. R., Salawitch, R., Canty, T., Lee-Taylor, J., Madronich, S., and Chance, K.: Impact of very short-lived halogens on stratospheric ozone abundance and UV radiation in a geo-engineered atmosphere, Atmos. Chem. Phys., 12, 10945-10955, https://doi.org/10.5194/acp-12-109452012, 2012.

Tilmes, S., Fasullo, J., Lamarque, J.-F., Marsh, D. R., Mills, M., Alterskjær, K., Muri, H., Kristjánsson, J. E., Boucher, O., Schulz, M., Cole, J. N. S., Curry, C. L., Jones, A., Haywood, J., Irvine, P. J., Ji, D., Moore, J. C., Karam, D. B., Kravitz, B., Rasch, P. J., Singh, B., Yoon, J.-H., Niemeier, U., Schmidt, H., Robock, A., Yang, S., and Watanabe, S.: The hydrological impact of geoengineering in the Geoengineering Model Intercomparison Project (GeoMIP), J. Geophys. Res.-Atmos., 118, 11036-11058, https://doi.org/10.1002/jgrd.50868, 2013.

van de Berg, W. J., van den Broeke, M., Ettema, J., van Meijgaard, E., and Kaspar, F.: Significant contribution of insolation to Eemian melting of the Greenland ice sheet, Nat. Geosci., 4, 679-683, https://doi.org/10.1038/ngeo1245, 2011.

Victor, D. G.: On the regulation of geoengineering, Oxf. Rev. Econ. Policy, 24, 322-336, https://doi.org/10.1093/oxrep/grn018, 2008. 
Weitzman, M. L.: The Geoengineered Planet, in: In 100 Years: Leading Economists Predict the Future, edited by: PalaciosHuerta, I., MIT Press, Cambridge, USA, 2014.

Wigley, T. M. L.: A combined mitigation/geoengineering approach to climate stabilization, Science, 314, 452-454, https://doi.org/10.1126/science.1131728, 2006.
Wolovick, M. J. and Moore, J. C.: Stopping the Flood: Could We Use Targeted Geoengineering to Mitigate Sea Level Rise?, The Cryosphere Discuss., https://doi.org/10.5194/tc-2018-95, in review, 2018.

Zhao, L., Yang, Y., Cheng, W., Ji, D., and Moore, J. C.: Glacier evolution in high-mountain Asia under stratospheric sulfate aerosol injection geoengineering, Atmos. Chem. Phys., 17, 6547-6564, https://doi.org/10.5194/acp-17-6547-2017, 2017. 